Technological University Dublin

ARROW@TU Dublin

2004-09-29

\title{
Structural Characterisation Of A Sol-Gel Copolymer Synthesised From Aliphatic And Aromatic Alkoxysilanes Using 29Si-NMR Spectroscopy
}

\author{
Mohamed Oubaha \\ Laboratoire des Mat'eriaux Inorganiques CNRS UMR 6002, Universit'e Blaise Pascal and Optical Sensors \\ Laboratory/National Centre For Sensor Research, School of Physical Science, Dublin City University, \\ mohamed.oubaha@tudublin.ie \\ M. Dubois \\ Laboratoire des Mat'eriaux Inorganiques CNRS UMR 6002, Universit'e Blaise Pascal \\ B. Murphy \\ Optical Sensors Laboratory/National Centre For Sensor Research, School of Physical Science, Dublin City \\ University
}

See next page for additional authors

Follow this and additional works at: https://arrow.tudublin.ie/cenresart

\section{Recommended Citation}

Oubaha, M. et al (2006) Structural Characterisation Of A Sol-Gel Copolymer Synthesised From Aliphatic And Aromatic Alkoxysilanes Using 29Si-NMR Spectroscopy, J Sol-Gel Sci Techn (2006) 38:111-119 doi:10.1007/s10971-006-7114-7

This Article is brought to you for free and open access by the Crest: Centre for Research in Engineering Surface Technology at ARROW@TU Dublin. It has been accepted for inclusion in Articles by an authorized administrator of ARROW@TU Dublin. For more information, please contact arrow.admin@tudublin.ie, aisling.coyne@tudublin.ie,gerard.connolly@tudublin.ie.

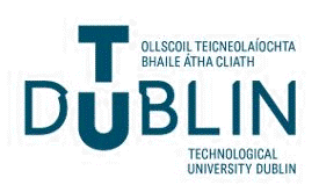


Authors

Mohamed Oubaha, M. Dubois, B. Murphy, and P. Etienne

This article is available at ARROW@TU Dublin: https://arrow.tudublin.ie/cenresart/57 


\title{
Structural characterisation of a sol-gel copolymer synthesised from aliphatic and aromatic alkoxysilanes using ${ }^{29} \mathrm{Si}-\mathrm{NMR}$ spectroscopy
}

\author{
M. Oubaha · M. Dubois · B. Murphy • P. Etienne
}

Received: 16 September 2004 / Accepted: 29 September 2004 / Published online: 1 May 2006

(C) Springer Science + Business Media, LLC 2006

\begin{abstract}
A hybrid organic-inorganic material was prepared from the hydrolytic co-condensation of 3trimethoxysilylpropylmethacrylate (MAPTMS) and diphenyldiethoxysilane (DPHDES). The synthesis was performed in three steps: (1) MAPTMS pre-hydrolysis, (2) addition of DPHDES, and (3) further hydrolysis of the obtained mixture. ${ }^{29} \mathrm{Si}$ nuclear magnetic resonance spectroscopy was used to characterise the structural evolution of the mineral network during the synthesis. It revealed the catalytic effect of DPHDES on the condensation reaction of silanol groups, initially observed for pre-hydrolysed MAPTMS. In addition, it was clearly demonstrated that the formation of the highest condensed species of the aromatic oligomers $\left(\mathrm{D}_{2}\right.$ species) occurred only in the presence of aliphatic oligomers, which decrease the sterical hindrance about the silicon nuclei.
\end{abstract}

\section{Introduction}

Sol-gel processing of siloxane-oxide hybrid materials [1] is a field of growing interest due to the wide variety of

\footnotetext{
M. Oubaha $(\bowtie) \cdot$ M. Dubois

Laboratoire des Matériaux Inorganiques CNRS UMR 6002,

Université Blaise Pascal, 24 Avenue des Landais, Aubière 63177,

France

e-mail: Mohamed.Oubaha@dcu.ie

M. Oubaha $\cdot$ B. Murphy

Optical Sensors Laboratory/National Centre For Sensor Research, School of Physical Science, Dublin City University,

Dublin 9, Ireland

P. Etienne

Laboratoire Des Verres, UMR 5587, Université de Montpellier II, Place Eugène Bataillon, Montpellier Cédex 5, 34090 France
}

potential applications of these systems [2-4]. The flexibility of the approach, resulting from the large variety of available precursors and low synthesis temperature, offers the potential molecular engineering of both composition and properties for a wide range of solid materials. For optical applications, organic/inorganic hybrid materials have gained increased importance over the last decade, mainly due to their simplicity of preparation in the fabrication of photonic devices for the second and third telecommunication windows, located respectively at 1310 and $1550 \mathrm{~nm}$ [5-9]. However, the main factor limiting the development of such devices has been high propagation losses caused by absorption and scattering effects within the material.

It is well known that $\mathrm{OH}$ and $\mathrm{CH}$ groups, both present in hybrid materials, compete with the propagation of the light by absorption processes involving their overtones and combinations [10]. Recently, the role of $\mathrm{OH}$ groups in the attenuation at $1550 \mathrm{~nm}$ has been reconsidered, as it was shown that the absorption by $\mathrm{CH}$ aliphatic groups induced stronger attenuation at this wavelength than $\mathrm{OH}$ groups [11, 12]. In addition, it was shown that $\mathrm{CH}$ aromatic groups do not induce any absorption at the aforementioned wavelength. Based upon these results, our attention has focused on the preparation, via the classical sol-gel route, of a new organic/inorganic hybrid material containing a reduced number of $\mathrm{CH}$ aliphatic groups. This was achieved through the incorporation of a reactive aromatic siloxane precursor (diethoxydiphenylsilane, DPHDES) into the material. Using multiple precursor species, a complex series of chemical reactions have been characterised for the sol-gel process [13]. The reactions may occur at each stage of the synthesis procedure, not only in solution (hydrolysis and condensation) but also during aging prior to gelation, and will therefore strongly influence the 
process of network formation and the final structure of the material.

The aim of this paper is the study of the structural evolution of the aforementioned material during the sol-gel synthesis in order to assess its suitability for the fabrication of telecommunication devices. The siloxane hybrid network formation has been monitored using liquid ${ }^{29} \mathrm{Si}-\mathrm{NMR}$ spec-troscopy. The various oxo-bridges formed through either self-condensation or co-condensation reactions between MAPTMS and DPHDES have been characterised.

\section{Experimental}

\subsection{The material}

The objective was to prepare via the hydrolytic sol-gel route, a material with a composition similar to that reported by Buestrich et al. [4].

The preparation was based upon the formation of a stable and homogeneous sol obtained from the mixture of two organically modified silicates in an equimolar ratio: MAPTMS (Assay 99\% in methanol) and DPHDES (Assay 97\% in ethanol). Both precursors were purchased form SigmaAldrich and used without further purification.

The difference in reactivity between the two alkoxides necessitated a three-step process. The pre-hydrolysis of the MAPTMS was followed by the addition of the pure DPHDES, and a further hydrolysis of the mixture.

\subsubsection{MAPTMS pre-hydrolysis}

MAPTMS was hydrolysed using an aqueous $0.01 \mathrm{~N} \mathrm{HCl}$ solution, with an alkoxide to water ratio of 1:0.75. As MAPTMS and water immiscible, the hydrolysis was performed in a heterogeneous manner. Following $20 \mathrm{~min}$ of stirring, the production of methanol became sufficient to permit the miscibility of all species present in the solution.

\subsubsection{DPHDES pre-hydrolysis}

Although not forming part of the actual synthesis process, a knowledge of the physical phenomena involved during hydrolysis of pure DPHDES is required to fully understand the structural evolution during synthesis of the hybrid material.

The first hydrolysis of DPHDES was carried out using the same process condition reported for MAPTMS. However, the direct hydrolysis of DPHDES resulted in the appearance of a white precipitate, composed of agglomerates created by the polycondensation of various entities during hydrolysis. Due to the sterical hindrance of the aromatic groups, hydrolysis would be expected to slow down. However, the opposite effect was observed and may be explained using electronic phenomena. As a result of the mesomeric effect aromatic molecules behave as electro-attractive moieties, resulting in an electronic deficiency on the silicon nuclei. This deficiency may be balanced by interaction with a strong nucleophilic group such as a water molecule. Therefore, in order to decrease the kinetics of reaction, hydrolysis of DPHDES was performed in a homogeneous way using an aqueous $0.01 \mathrm{~N} \mathrm{HCl}$ solution diluted with ethanol. A final molar ratio of 0.5:1:1 (DPHDES: $\mathrm{H}_{2} \mathrm{O}$ : Ethanol) was employed.

\subsubsection{Sol-gel synthesis of an aliphatic and aromatic hybrid copolymer}

After $45 \mathrm{~min}$, pure DPHDES was added dropwise to the partially hydrolysed MAPTMS. The reaction is exothermic in nature. Following a further $45 \mathrm{~min}$, the addition of water $(\mathrm{pH} 7)$ was carried out, in order to achieve a hydrolysis rate of $100 \%$ (alkoxide/water $=1$ ).

This second hydrolysis produces to a stable and homogeneous sol only when the first hydrolysis of the MAPTMS is carried out using the aforementioned conditions. For lower hydrolysis rates or higher hydrolysis times, a white precipitate appears.

\subsection{Characterisation of the sol during the synthesis}

The formation of the siloxane-oxide hybrid network may be followed using solution ${ }^{29} \mathrm{Si}-\mathrm{NMR}$ spectroscopy. ${ }^{29} \mathrm{Si}$ (nuclear spin 1/2) exhibits a natural abundance of $4.7 \%$. It is 2.1 times more sensitive than ${ }^{13} \mathrm{C}$, but is typically characterised by long spin relaxation times [14]. As single-pulse experiments necessitate both relatively long recycle delay times and accumulations, measurement times up to 15-30 min may be expected for concentrated systems $(\mathrm{c}(\mathrm{Si}) \geq 1 \mathrm{M})$ such as those involved in current sol-gel preparations. The technique permits identification of the various species present in a solution at short times (less than $30 \mathrm{~min}$ ) and may be used for the characterisation of the various oxobridges formed through either self-condensation ( $\mathrm{Si}-\mathrm{O}-\mathrm{Si}$ ) [15] or co-condensation ( $\mathrm{Si}-\mathrm{O}-\mathrm{M}, \mathrm{M}=$ mineral atom) [16] reactions between organically modified alkoxysilanes and the metal alkoxides. Babonneau et al. have demonstrated the formation of a copolymer from short aliphatic chain hybrid monomers [16]. To our knowledge, no similar studies have been performed with aromatic alkoxysilanes.

\section{3. ${ }^{29} \mathrm{Si}-\mathrm{NMR}$ spectroscopy}

Spectra obtained from liquid solution were recorded at room temperature. Accumulation parameters are presented 
Table 1 Experimental acquisition conditions for ${ }^{29} \mathrm{Si}$ NMR spectroscopy

\begin{tabular}{llllll}
\hline State & $\begin{array}{l}\text { Frequency } \\
(\mathrm{MHz})\end{array}$ & $\begin{array}{l}\text { Recycle } \\
\text { delay } \\
\text { time (s) }\end{array}$ & $\begin{array}{l}\text { Pulse } \\
\text { duration }\end{array}$ & $\begin{array}{l}\text { Spectral } \\
\text { width } \\
(\mathrm{ppm})\end{array}$ & Scans \\
\hline Liquid & 46.69 & 4 & $6 \mu \mathrm{s}$ & 500 & 200 \\
\hline
\end{tabular}

in Table 1. The chemical shifts were referenced with respect to tetramethylsilane (TMS), used as external reference. The FID processing used a $10 \mathrm{~Hz}$ line broadening.

All times reported on experimental NMR spectra illustrate the duration of the chemical reaction characterised. They also represent the start point of NMR acquisition. Each recorded spectrum is an average of all spectra obtained during the instrument acquisition time.

\section{Results}

\subsection{MAPTMS pre-hydrolysis}

The ${ }^{29} \mathrm{Si}$ NMR spectrum of pure MAPTMS alkoxide (not shown) displays a single peak at -42.8 ppm demonstrating the absence of any hydrolysed or condensed species. Such species are expected at lower chemical shifts as shown previously for MAPTMS [13] and analogous structures [17-20]. The hydrolysis and condensation of the precursor may, therefore, be monitored using NMR spectroscopy.

Classical $T$ notation was used for the different silicate species, identifying the number of oxygen bridging atoms; $i$ and $j$ postscripts represent the number of oxo bridges and hydroxyl functions, respectively. Although relatively insensitive to subtle details in molecular structures, NMRspectroscopy allows for the distinction and quantitative evolution of the relative contributions of silicon atoms with 0,1 , 2 or 3 siloxanes bridges. The species formed during the hydrolysis-condensation reactions were characterised and are reported in Table 2.

The hydrolysis-condensation reactions were followed for four days (Fig. 1). After $28 \mathrm{~min}$, the spectrum exhibited four resonances at $-42.3,-41.4,-40.6$ and $-40.1 \mathrm{ppm}$. The peak corresponding to the monomer $T_{0}^{0}$ is observed at $-42.3 \mathrm{ppm}$. This position is slightly shifted relative to the value of the pure alkoxide ( $-42.8 \mathrm{ppm})$. A similar behaviour has been previously observed for phenyltrimethoxysilane and dimethyldiethoxysilane [17-19]. The three signals located at $-41.4,-40.6$ and $-40.1 \mathrm{ppm}$ can be attributed to $T_{0}^{1}, T_{0}^{2}$ and $T_{0}^{3}$ species respectively. The substitution of a methoxy group with a hydroxyl group induces a conventional downfield shift as observed for tetrafunctional alkoxides [21].
Table 2 Assignments of ${ }^{29} \mathrm{Si}-\mathrm{NMR}$ signals for monomeric and oligomeric species obtained from the MAPTMS hydrolysiscondensation

\begin{tabular}{lll}
\hline & Notation & Chemical shift $(\mathrm{ppm})$ \\
\hline $\mathrm{RSi}(\mathrm{OMe})_{3}$ & $T_{0}^{0}$ & -42.3 \\
$\mathrm{RSi}(\mathrm{OMe})_{2} \mathrm{OH}$ & $T_{0}^{1}$ & -41.4 \\
$\mathrm{RSiOMe}(\mathrm{OH})_{2}$ & $T_{0}^{2}$ & -40.6 \\
$\mathrm{RSi}(\mathrm{OH})_{3}$ & $T_{0}^{3}$ & -40.1 \\
$\mathrm{RSi}(\mathrm{OMe})_{2}-\mathrm{O}-\mathrm{Si}$ & $T_{0}^{1}$ & -49.9 \\
$\mathrm{RSi}(\mathrm{OMe}) \mathrm{OH}-\mathrm{O}-\mathrm{Si}$ & $T_{1}^{1}$ & -50.5 \\
$\mathrm{RSi}(\mathrm{OH})_{2}-\mathrm{O}-\mathrm{Si}$ & $T_{1}^{2}$ & -49.3 \\
$\mathrm{RSi}(\mathrm{OMe})-(\mathrm{O}-\mathrm{Si})_{2}$ & $T_{2}^{0}$ & -59.1 \\
$\mathrm{RSi}(\mathrm{OH})-(\mathrm{O}-\mathrm{Si})_{2}$ & $T_{2}^{1}$ & -58.5 \\
$\mathrm{RSi}(\mathrm{OSi})_{3}$ & $T_{3}$ & -67.4 \\
\hline
\end{tabular}

After 28 min of reaction, a peak is already present in the $T_{1}$ region, situated at $-49.2 \mathrm{ppm}$. The first peak in the $T_{2}$ region (at $-59.1 \mathrm{ppm}$ ) appears after one day of reaction while the first peak in the $T_{3}$ region (at $-67.4 \mathrm{ppm}$ ) appears after four days of reaction.

Therefore, the formation of simple siloxane bonds $T_{1}^{0}, T_{1}^{1}$ and $\left(T_{1}^{2}\right)$ commences within the first minutes of reactions, whereas the formation of more condensed species $\left(T_{2}^{0} \mathrm{y}\right.$ and $T_{2}^{1}$ ) begins only after $24 \mathrm{~h}$ of reaction, when to species concentration begins to decrease.

\subsection{DPHDES hydrolysis}

The ${ }^{29} \mathrm{Si}$-NMR spectrum of the pure DPHDES alkoxide (Fig. 2) displays a single peak at -31.4 ppm demonstrating as for pure MAPTMS, the absence of any hydrolysed or condensed species. As DPHDES contains only two reactive alkoxide groups, the classical $D_{i}^{j}$ notation was used; where $i$ and $j$ postscripts represent the number of oxo-bridges and hydroxyl functions, respectively. The hydrolysis-condensation reactions of DPHDES were also followed for four days.

After one hour of reaction, the spectrum contained only a single peak located at $-29.7 \mathrm{ppm}$. As siloxane groups are always located at higher chemical shifts than the associated alkoxide precursor, this peak may not be assigned to such species. The observed peak may be assigned to a silanol bond $\left(D_{0}^{1}\right.$ or $\left.D_{0}^{2}\right)$. Furthermore, no condensed entity was identified displaying a lower kinetic of condensation than for MAPTMS.

After six hours of reaction a significant peak appears at - $36.4 \mathrm{ppm}$. According to literature [21], a progressive increase in the number of siloxane bonds induces a shift of between 7 and 10 ppm towards higher chemical shift. The peak observed at $-36.4 \mathrm{ppm}$ may be assigned to $D_{1}$ species. However, no structural study has been previously reported for DPHDES and therefore at this stage we cannot fully identify the degree of condensation of the observed shift. 
Spectra recorded after one and two days of reaction show an increase of the peak located at $-36.4 \mathrm{ppm}$, with a corresponding decrease of the peak located at $-29.7 \mathrm{ppm}$. This phenomenon identifies the continuation of poly-condensation reactions. The disappearance of the $D_{0}$ peak following two days of reaction, and the weak width $(1 \mathrm{ppm})$ of the only observed peak $(-36.4 \mathrm{ppm})$ demonstrate that the system is essentially composed of oligomers of similar sizes and that the degree of condensation of the silicon atom is rigorously identical $\left(D_{1}\right.$ or $\left.D_{2}\right)$.

After four days of reaction, it is observed that the peak located at $-36.4 \mathrm{ppm}$ has moved to a higher chemical shift at $-37.7 \mathrm{ppm}$. This shift is not sufficient to demonstrate a change in the degree of condensation of the silicon atom, but may result from an increase in the sterical hindrance around the silicon atom due to growth of the oligomers.
Figure 1. ${ }^{29} \mathrm{Si}-\mathrm{NMR}$ spectra of MAPTMS pre-hydrolysis during four days of aging

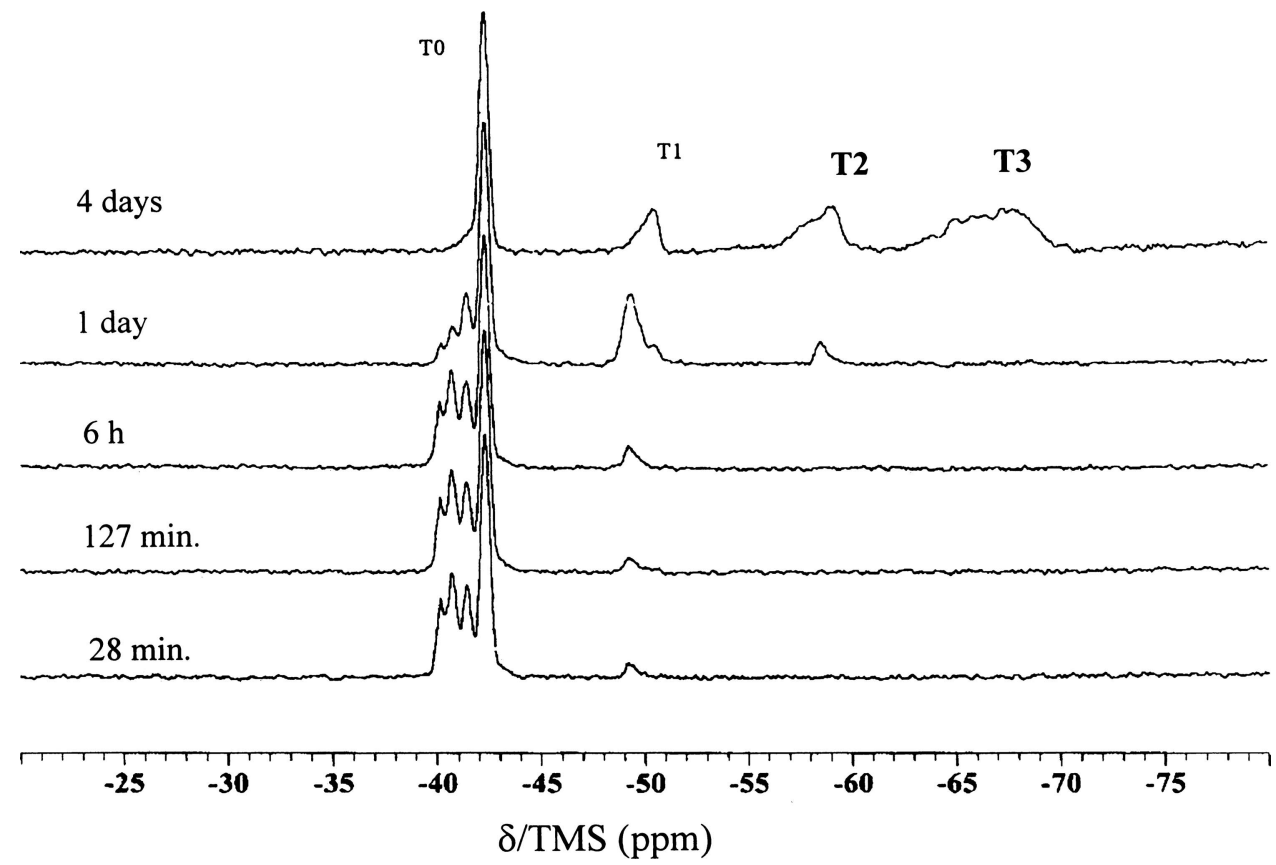

Figure $2{ }^{29} \mathrm{Si}-\mathrm{NMR}$ spectra of DPHDES pre-hydrolysis during four days of aging

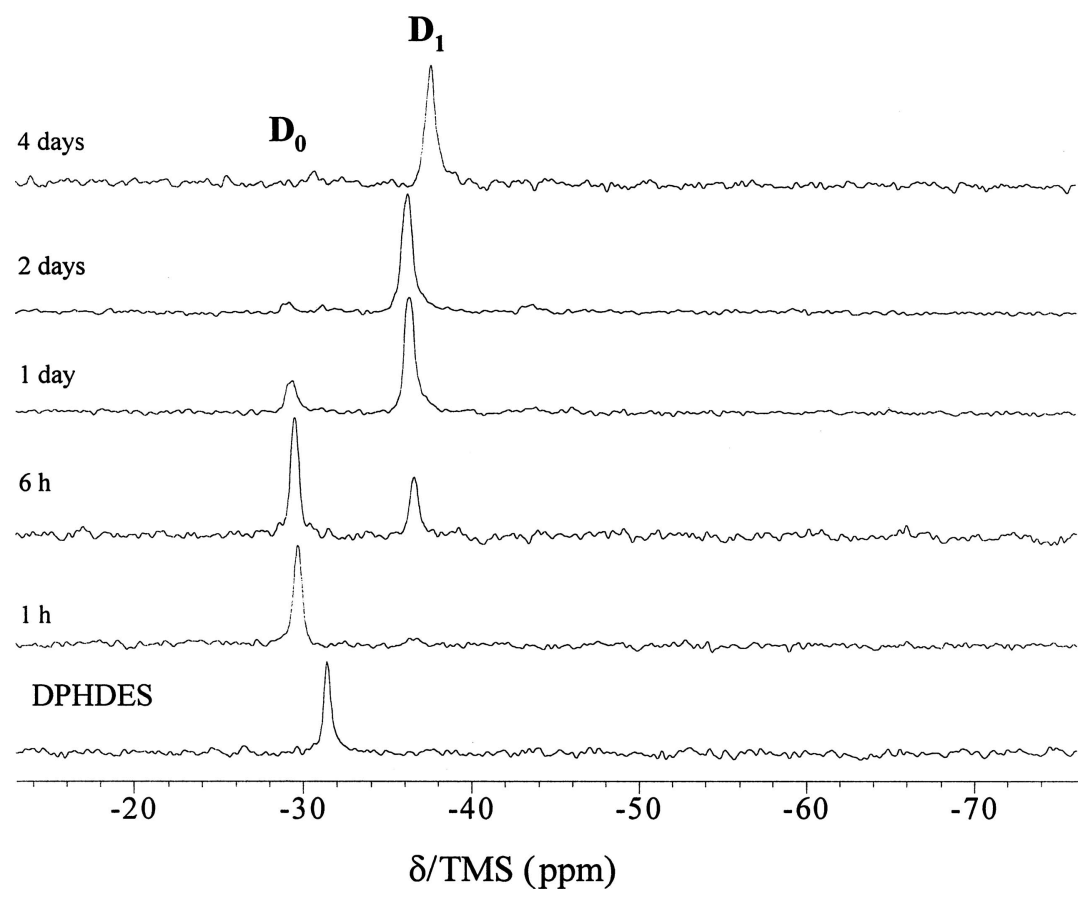


Figure $3{ }^{29} \mathrm{Si}-\mathrm{NMR}$ spectra of sample M (mixture of pre-hydrolysed MAPTMS and pure DPHDES), $M_{1}$ (hydrolysed $M$ following $30 \mathrm{~min}$ of reaction), $M_{2}$ (hydrolysed $M$ following one day of reaction) and $M_{3}$ (hydrolysed $M$ following one month of reaction)

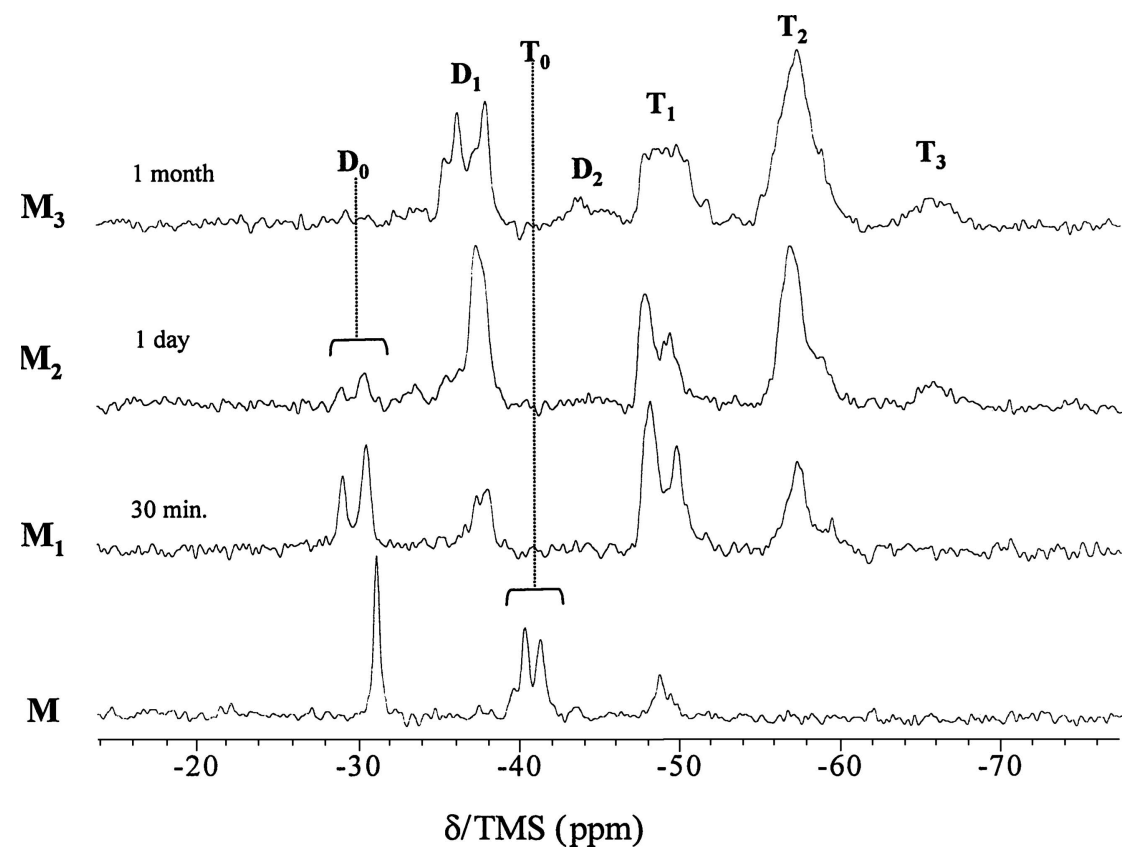

\subsection{Intermediates steps}

Figure 3 displays the ${ }^{29} \mathrm{Si}-\mathrm{NMR}$ spectra of samples from the mixture of pre-hydrolysed MAPTMS with pure DPHDES $(M)$ and at various reaction times $\left(M_{1}=30 \mathrm{~min}, M_{2}=\right.$ $24 \mathrm{~h}$ and $M_{3}=$ one month) after hydrolysis.

Spectrum $M$, recorded immediately after mixing shows the disappearance of $T_{0}{ }^{3}$, the decrease of both $T_{0}{ }^{1}$ and $T_{0}{ }^{2}$, and the presence of $T_{1}$. Furthermore, the peak relating to the DPHDES precursor is slightly shifted towards a lower chemical shift ( $-30.9 \mathrm{ppm}$ ) compared with pure DPHDES initially located at $-31.4 \mathrm{ppm}$.

Spectrum $M_{1}$, obtained after the hydrolysis of $M$, identifies two clear phenomena occurring in the $T$ and $D$ regions. In the $T$ region, we observe the disappearance of all $T_{0}{ }^{1}$ species, previously identified around $-40 \mathrm{ppm}$. In addition, an increase of the initial $T_{1}$ species is evident, and the appearance of a peak located at $-49.9 \mathrm{ppm}$ characterises the formation of a new environment around silicon atoms in the ti configuration. The spontaneous appearance of two peaks at -57.5 and $-59 \mathrm{ppm}$ signal the formation of $T_{2}$ species. For both $T_{1}$ and $T_{2}$ groups, two peaks are observed instead of the one previously seen for the self-condensation of MAPTMS. In the $D$ region, we observe the total disappearance of the precursor peak $(-31.4 \mathrm{ppm})$, the appearance of two do signals ( -29.2 and $-30.6 \mathrm{ppm}$ ) and two signals located at -37.7 and $-38.8 \mathrm{ppm}$ relating to siloxane bonds. As previously indicated, the distinction between $D_{1}$ or $D_{2}$ signals cannot be fully identified at this point due to the limited amount of NMR data available for similar materials.
Spectrum $M_{2}$, obtained after one day of reaction, shows a decrease of $T_{1}$, an increase of $T_{2}$, and the appearance of $T_{3}$ as a broad band located around $-66 \mathrm{ppm}$. $D$ species follows a similar behaviour. A drastic decrease of $D_{0}$ species can be observed, whereas the band located at -37.7 ppm, previously assigned to $D_{1}$ or $D_{2}$ species, grows rapidly. However, the presence of a shoulder illustrates a possible contribution from a peak around $-38.8 \mathrm{ppm}$. One can also observe the appearance of two smaller peaks at -35.1 and $-36.7 \mathrm{ppm}$, probably related to the contribution from species similar nature to that identified at $-37.7 \mathrm{ppm}$.

Spectrum $M_{3}$, obtained after one month of reaction, indicates a large widening of the band relating to the $T_{1}$ species. The broadening result from the superimposition of the $\mathrm{T}_{2}$ peaks observed in $M_{2}$ and two new peaks at higher positions ( -50 and $-51 \mathrm{ppm})$. It also illustrates an increase in $T_{2}$ groups and a widening of the $T_{3}$ band. For $D$ species, one can observe the appearance of two resonances located at -35 and $-36.2 \mathrm{ppm}$ demonstrating the formation of two new condensed species. The appearance of a new broad band between -44 and $-46 \mathrm{ppm}$ is also evident.

\section{Discussion}

Results obtained from the individual hydrolysis of the two alkoxides precursors show, in both cases, a slow rate of condensation with reaction times of up to six hours observed. For MAPTMS, the sol is mainly composed of a mixture of small oligomers of $T_{0}$ species following six hours of reactions. Following the same time-period, DPHDES is composed of 
a mixture of $D_{0}$ and $D_{1}$ species, with a concentration ratio of 1:0.5 $\left(D_{0}: D_{1}\right)$. On this basis, for both alkoxides, the appearance of higher condensed species at lower aging times in further steps of the material preparation cannot be attributed solely to the aging effect, but also to a further hydrolysis and/or to the introduction of a catalytic agent.

\subsection{Spectrum $M$}

The shift toward lower chemical values observed for the aromatic silicon nuclei peak indicates a slight decrease in its electron density. Similar behaviours have been previously observed in literature. Babonneau et al. [22] reported possible alkoxy-exchange reactions between ethanol and methoxysilane bonds, allowing the formation of ethoxysilan and methanol. Also, in previous work [13], our group identified $\mathrm{OH}$-exchange reactions between different alkoxides. Both reactions are possible but because of the low chemical shift $(0.6 \mathrm{ppm})$ observed, the alkoxy-exchange reactions proposed as the most likely phenomenon. The appearance of a peak at $-49.5 \mathrm{ppm}$, not observed during the MAPTMS hydrolysis, suggests the presence of a second higher electron density silicon environment for $T_{1}$ species. This behaviour can be attributed to the formation of $T_{1}$-D species. The peak related to $D_{1}$ species ( $-37.6 \mathrm{ppm}$ ) not highly visible in this spectrum (at $-37.6 \mathrm{ppm}$ ) is confirmed in the following steps of the characterisation (samples $M_{1}, M_{2}$ and $M_{3}$ ). Furthermore, to peaks are strongly reduced with $T_{1}$ species greatly enhanced.

Based upon the results, the observed phenomena for both $D$ and $T$ species appears linked. The alkoxy-exchange reaction induces the catalysis of the condensation reaction of siloxane bonds. All the chemical reactions implied can be summarised in the following scheme:

$$
\begin{aligned}
& 2 \mathrm{R}-\mathrm{Si}(\mathrm{OH})_{v}(\mathrm{OMe})_{w}+\mathrm{Ph}_{2} \mathrm{Si}(\mathrm{OEt})_{2} \\
& \rightarrow \mathrm{R}-\mathrm{Si}-\mathrm{O}-\mathrm{Si}-\left(\mathrm{R} \mathrm{or} \mathrm{Ph}_{2}\right)+\mathrm{Ph}_{2} \mathrm{Si}(\mathrm{OEt})_{x}(\mathrm{OMe})_{y} \\
& +z \mathrm{EtOH}
\end{aligned}
$$

where $\mathrm{R}$ and $\mathrm{Ph}$ represent the methacryloxypropyl and the phenyl groups respectively. Both $\mathrm{v}$ and $\mathrm{w}$ subscripts may vary between 0 and 3 , whereas $x, y$ and $z$ may vary between 0 and 2.

\subsection{Spectrum $M_{1}$}

The formation of $M_{1}$ is accompanied by an increase of siloxane bonds. The total disappearance of $T_{0}$ species indicates that hydrolysis acts as a catalyst for the formation of siloxane bonds. This behaviour is contrary to the initial individual hydrolysis, which revealed the formation of all $T_{0}$ species. However, the formation of $D_{0}{ }^{1}$ and $D_{0}{ }^{2}$

\begin{tabular}{|c|c|c|}
\hline & Notation & $\begin{array}{l}\text { Chemical shift (ppm) } \\
\pm 0.1 \mathrm{ppm}\end{array}$ \\
\hline $\mathrm{Ph}_{2} \mathrm{Si}(\mathrm{OH})_{2}$ & $D_{0}^{2}$ & -29.2 \\
\hline $\mathrm{Ph}_{2} \mathrm{Si}(\mathrm{OH})(\mathrm{OEt})$ & $D_{0}^{1}$ & -30.61 \\
\hline $\mathrm{Ph}_{2} \mathrm{Si}-\mathrm{O}-\mathrm{SiPh}_{2}$ & $D_{1}$ & -37.7 \\
\hline $\mathrm{Ph}_{2} \mathrm{Si}-\mathrm{O}-\mathrm{SiR}$ & $D_{1}-T$ & -38.8 \\
\hline $\mathrm{RSi}-\mathrm{O}-\mathrm{SiPh}_{2}$ & $T_{1}-D$ & -48.3 \\
\hline $\mathrm{RSi}-\mathrm{O}-\mathrm{Si}$ & $T_{1}$ & -49.9 \\
\hline $\mathrm{RSi}\left(-\mathrm{OSiPh}_{2}\right)(-\mathrm{OsiR})$ & $T_{2}-\mathrm{D}$ & -57.5 \\
\hline $\mathrm{RSi}(-\mathrm{OSiR})_{2}$ & $T_{2}$ & -59 \\
\hline
\end{tabular}

Table 3. Assignment of ${ }^{29} \mathrm{Si}-\mathrm{NMR}$ signals for monomeric and oligomeric species present in sample $M_{1}$

silanol groups demonstrates that $D$ groups display a lower kinetic of condensation than that of $T$ groups. Retrospectively, this result allows the assignment of the peak observed at $-29.7 \mathrm{ppm}$ in Fig. 2, to the hydrolysis of DPHDES to $D_{0}{ }^{1}$ species.

The presence of two different environments for both $T_{1}$ and $T_{2}$ groups, clearly different from those observed for the self-condensation of MAPTMS, reveal new configurations around $T_{1}$ and $T_{2}$ silicon atoms. Furthermore, the formation of a second $D_{1}$ peak, at a higher chemical shift is proof of a second configuration around the di silicon atom, as occurred for $T_{1}$ and $T_{2}$ groups. Consequently, these two phenomena provide evidence of the formation of siloxane bonds between the two hybrids. Such bonds will be denoted $D-T$.

Finally, sample $M_{1}$ is composed of a mixture of oligomers of varying statistical size. An assignment of the NMR signals for both monomeric and oligomeric species is presented in Table 3.

\subsection{Spectrum $M_{2}$}

The reduction in the species with a low degree of condensation $\left(D_{0}\right.$ and $\left.T_{1}\right)$ in favour of more condensed entities $\left(D_{1}\right.$, $T_{2}$ and $T_{3}$ ) highlights that the reactions of poly-condensation progress regularly in time. Although changing in intensity, the respective chemical shift of each species remain unchanged compared to spectrum $M_{1}$. Therefore, all the molecular entities previously identified (Table 3) are also present in sample $M_{2}$ but at different concentrations. The evolution of the relative proportion of these entities will be analysed in Section 4.5.

\subsection{Spectrum $M_{3}$}

The appearance of new $T_{1}$ and $D_{1}$ entities, located at higher and lower chemical shifts respectively than those observed for the independent hydrolyses, illustrates opposite effects on each nuclei. The electron density is decreased on the $D$ silicon atom whereas it is increased on the $T$ silicon atom. 
Table 4 Assignment of ${ }^{29} \mathrm{Si}-\mathrm{NMR}$ signals for oligomeric species present in sample $M_{3}$

\begin{tabular}{|c|c|c|}
\hline & Notation & $\begin{array}{l}\text { Chemical shift } \\
(\mathrm{ppm}) \pm 0.1 \mathrm{ppm}\end{array}$ \\
\hline $\mathrm{Ph}_{2} \mathrm{Si}-\mathrm{O}-\mathrm{SiR}$ & $D_{1}-T_{1}$ & -35 and -36.2 \\
\hline $\mathrm{Ph}_{2} \mathrm{Si}-\mathrm{O}-\mathrm{SiPh}_{2}$ & $D_{1}-D_{1}$ & -37.7 \\
\hline $\mathrm{Ph}_{2} \mathrm{Si}-\mathrm{O}-\mathrm{SiR}-\mathrm{OSi}$ & $D_{1}-T_{2}$ & -38.8 \\
\hline $\begin{array}{c}\mathrm{Ph}_{2} \mathrm{Si}-\mathrm{O}-\mathrm{SiPh}_{2}-\mathrm{OSi} \text { and } \\
\mathrm{Ph}_{2} \mathrm{Si}-\mathrm{O}-\mathrm{SiR}(-\mathrm{OSi})_{1 ; 2}\end{array}$ & $\begin{array}{c}D_{2}-D_{1} \text { and } \\
D_{2}-T_{2 ; 3}\end{array}$ & -44 \\
\hline $\mathrm{RSi}-\mathrm{O}-\mathrm{SiR}$ & $T_{1}$ & -47.2 and -48 \\
\hline $\mathrm{RSi}-\mathrm{O}-\mathrm{SiPh}_{2}$ & $T_{1}-D_{1}$ & -49 \\
\hline $\mathrm{RSi}-\mathrm{O}-\mathrm{SiPh}_{2}-\mathrm{OSiR}$ & $T_{1}-D_{2}$ & -50 \\
\hline $\mathrm{RSi}-\mathrm{O}-\mathrm{SiPh}_{2}-\mathrm{OSiPh}_{2}$ & $T_{1}-D_{2}$ & -51 \\
\hline $\mathrm{RSi}-(\mathrm{O}-\mathrm{SiR})_{2}$ & $T_{2}$ & -57.9 \\
\hline $\begin{array}{l}\mathrm{RSi}-\left(\mathrm{O}-\mathrm{SiPh}_{2}\right)(\mathrm{O}-\mathrm{SiR}) \text { and } \\
\mathrm{RSi}-(\mathrm{O}-\mathrm{SiR})\left[\mathrm{O}-\mathrm{SiPh}_{2}(\mathrm{O}-\mathrm{Si})\right]\end{array}$ & $\begin{array}{l}T 2-D_{1} \text { and } \\
T_{2}-D_{2}\end{array}$ & -59 \\
\hline $\begin{array}{l}\mathrm{RSi}(\mathrm{OSiR})_{3} \text { and } \\
\mathrm{RSi}(\mathrm{OSiR})_{2}\left(\mathrm{OSiPh}_{2}\right)\end{array}$ & $T_{3}$ & -66 \\
\hline
\end{tabular}

This phenomenon can be explained by the formation of $D-T$ siloxane bonds, which are responsible of the simultaneous opposite shifts. Certainly, the methacry-loxypropyl group displays a lower sterical hindrance than the contribution of two phenyl groups (DPHDES). The resulting effect is a relaxation on the silicon atom.

Consequently the peaks located at -35 and $-36.2 \mathrm{ppm}$ can both be assigned to $D_{1}-T_{1}$. The peaks located at -49.5 and $-51 \mathrm{ppm}$ can be assigned to $T_{1}-D_{2}$. This conclusion highlights the appearance of $D_{2}$ peaks, which may be located between $D_{1}$ and $T_{1}$ positions.

Based upon the results, the band centred at $-44 \mathrm{ppm}$ may be attributed $D_{2}$ species. As observed for the selfcondensation of MAPTMS (Fig. 1) and in accordance with literature [21], a progressive increase in the number of siloxane groups results in an increase of between 7 to $10 \mathrm{ppm}$ in chemical shift. For example, with a lower chemical shift corresponding to $T_{0}{ }^{3}$ previously observed at $-40.1 \mathrm{ppm}$, the first $T_{1}$ line is expected around $-47 \mathrm{ppm}$. Therefore, with the $D_{1}$ peak previously observed at $-37.7 \mathrm{ppm}$, the peak at $-44 \mathrm{ppm}$ may be ascribed to $D_{2}$ groups. Therefore, it describes the formation of two siloxane bonds on a silicon atom belonging to the aromatic precursor. As no $D_{2}$ group was observed for DPHDES hydrolysis (Fig. 2), the peak at $-37.7 \mathrm{ppm}$ may be assigned to $D_{1}$ species (Table 4).

This result demonstrates that the formation of $D_{2}$ groups becomes possible only with the presence of aliphatic oligomers. This is facilitated by a decrease of sterical hindrance.

The observed widening of the $T_{3}$ band previously observed is not caused by the formation of $T_{3}-D$ bonds, but result from an increase in electron density around closed
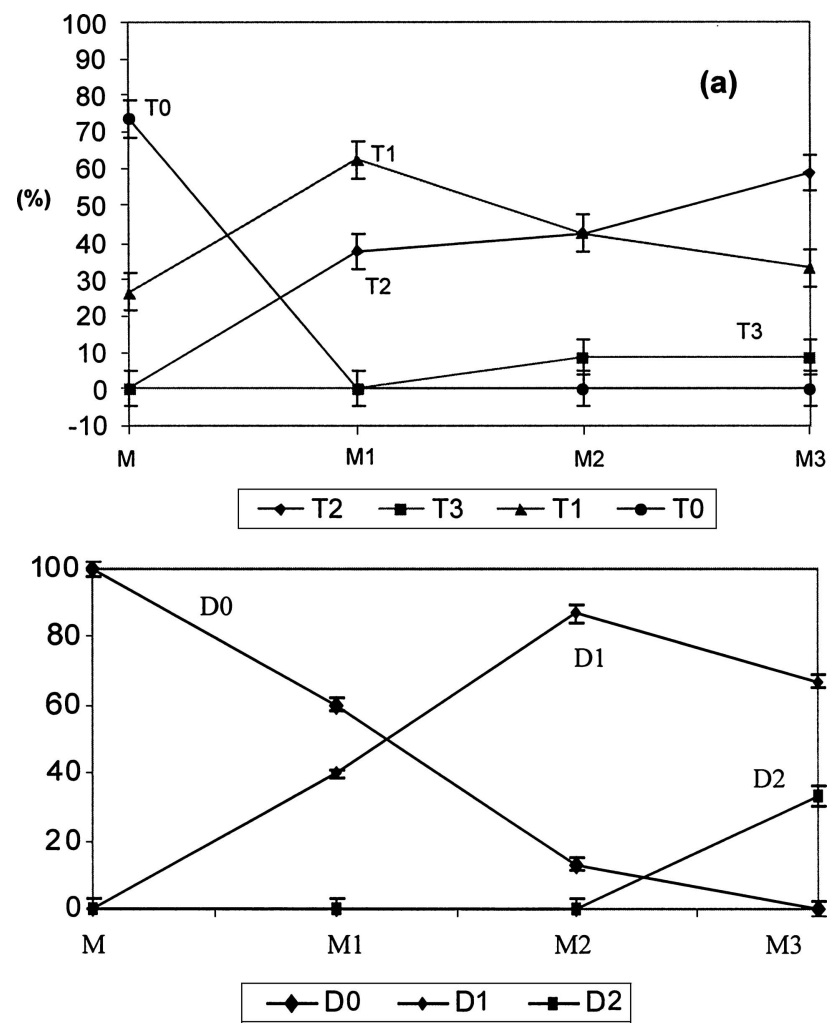

Figure 4 Evolution of the $T_{i}$ (a) and $D_{i}$ (b) species concentration as a function of the different steps of the synthesis. Lines are shown as a guide for the eye

$T_{1}$ or $T_{2}$ silicon atoms which have reacted with aromatic oligomers. From a qualitative point of view, after one month of aging, the sol is essentially composed of oligomers of various statistical sizes. In order to complete the structural evaluation, quantitative studies were performed. The results of the study are summarised in the following section.

\subsection{Quantitative evolution}

The quantitative evolution of all $D$ and $T$ species during the material preparation is plotted as a function of reaction steps (Fig. 4). The figures demonstrate that initial hydrolysis results in the decrease of $D_{0}$ and $T_{0}$ concentrations, the increase of $T_{1}$ species, and the formation of $D_{1}$ and $T_{2}$ species. Hydrolysis spontaneously induces a $40 \%$ decrease of $D_{0}$ species and the total disappearance of $T_{0}$ species, with the production of $D_{1}, T_{1}$ and $T_{2}$ species for which the proportions increase by 40,36 and $37 \%$, respectively.

Aging effects lead, following $24 \mathrm{~h}$ of reaction, to the appearance of $T_{3}$ groups (9\% contributions), and a significant increase of $D_{1}$ and $T_{2}$ species (87 and $43 \%$ contributions respectively), and the decrease of $D_{0}$ and $T_{1}$ groups. Following one month of aging, the contribution of $T_{3}$ species remains 
at $9 \%$, while that of $T_{2}$ increases to $58 \%$ to the detriment of $T_{1}$ species, which decreases to $33 \% . D_{2}$ species also appear with a contribution of $33 \%$, to the detriment of $D_{0}$ and $D_{1}$ groups. The appearance of $D_{2}$ groups occurs simultaneously with an increase of $T_{2}$, a decrease of $T_{1}$, and a stagnation of $T_{3}$ species. This result suggests that the insertion of aromatic oligomers into aliphatic species occurs preferentially on $T_{2}$ sites. However, from a physical standpoint, this result is not plausible as $T_{1}$ groups, with lower sterical hindrance, are more susceptible to reaction with the larger aromatic oligomers. On this basis, it is advisable to study the evolution of the relative contribution of each oxo-bridges species: $T_{1}-T$, $T_{1}-D, T_{2}-T$ and $T_{2}-D$ (Table 4).

Figure 5 presents the evolution of the aforementioned species during the synthesis. After sample $M$ preparation, siloxane species are essentially present in the $T_{1}$ form. The two following steps (hydrolysis and aging up to one day) illustrate that $T_{1}$ species are present in relatively similar proportions in both the polymeric $\left(T_{1}-T\right)$ and co-polymeric $\left(T_{1}-D\right)$ forms. At the end of the synthesis, $T_{1}-D(68 \%)$ are the prevailing groups, with less $T_{1}-T$ present (32\%). $T_{2}$ groups, however, behave differently. They appear during the hydrolysis step essentially as polymeric species $\left(T_{2}-T\right)$ with an $85 \%$ concentration. This value remains almost constant up to the end of the synthesis. It is clear that aromatic groups are preferentially grafted onto $T_{1}$ species. This may result from the lower sterical hindrance of $T_{1}$ groups, which allows the connection of the reactive silane functions to form siloxane bonds.

The analysis allows for the quantitation of the various oxo-bridges formed during material preparation and for the extraction of valuable qualitative structural information. Indeed, the insertion of aromatic oligomers within the aliphatic structure occurs through the formation of $T_{1}-D$ chemical bonds.

\section{Conclusion}

A hybrid organic-inorganic material has been prepared from the hydrolytic co-condensation of MAPTMS and DPHDES. An in-depth study of the structural evolution of the mineral network has been performed using ${ }^{29} \mathrm{Si}-\mathrm{NMR}$ spectroscopy. The catalytic effect of DPHDES on the condensation of silanol groups has been highlighted. Also, it has been clearly demonstrated that the formation of the highest condensed species of the aromatic oligomer ( $D_{2}$ species) is formed only in the presence of aliphatic oligomers, which decrease the sterical hindrance around the silicon nuclei. The prepared material is homogeneous at the molecular level and will act as a potential candidate for future photonic applications.
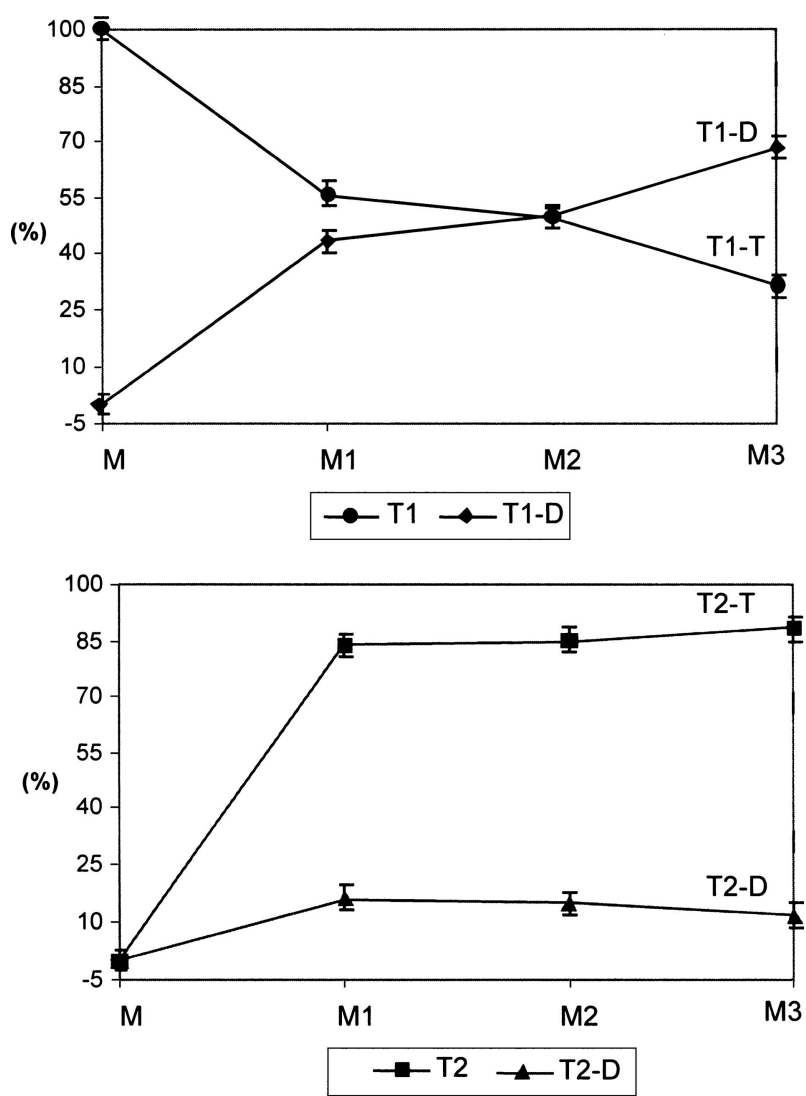

Figure 5 Evolution of the $T_{i}-D$ species concentration as a function of the different steps of the synthesis. Lines are shown as a guide for the eye

\section{References}

1. C. Sanchez and F. Ribot, New J. Chern. 18, 1007 (1994).

2. H. Schmidt, J. Sol-Gel Sci. Technol. 1, 217 (1994).

3. C. Roscher, R. Buestrich, P. Dannberg, O. Rosch, and M. Popall, Mater. Res. Soc. Symp. Proc. 519, 239 (1998).

4. R. Buestrich, F. Khalenberg, M. Popall, A. Martin, and O. Rosch, Mater. Res. Soc. Symp. Proc. 628, CC9.8.1 (2000).

5. H. Krug, F. Teillantes, P.W. Oliviers, and H. Schmidt, Proc. SPIE 1758, 448 (1992).

6. H.W. Schneider, Mater. Res. Soc. Symp. Proc. 244, 337 (1992).

7. M.E. Robertson, O.-J. Hagel, G. Gustafsson, A. Dabek, M. Popall, L. Cergel, P. Wennekers, P. Kiely, M. Lebby, and T. Lindahl, ECTC Electronic Components and Technology Conference, pp. 1413 (1998).

8. J. Porque, P. Coudray, R. Charters, K. Kribich, P. Etienne, and Y. Moreau, Opt. Comm. 183(1-4), 45 (2000).

9. R. Houbertz, G. Domann, C. Cronauer, A. Schmitt, H. Martin, J.-U. Park, L. Fröhlich, R. Buestrich, M. Popall, U. Streppel, P. Dannberg, C. Wächter and A. Bräuer, Thin Solid Film 442, 194 (2003).

10. M. Mennig, M. Zahnhaussen, and H. Schmidt, Proc. SPIE 3469, 68 (1998).

11. M. Oubaha, P. Etienne, S. Galas, P. Coudray, J.M. Nedelec, and Y. Moreau, J. Sol-Gel Sci. Technol. 33, 241 (2005).

12. M. Oubaha, P. Etienne, S. Calas, R. Sempere, J.M. Nedelec, and Y. Moreau, Journal of Non-Crystalline Solids. 351, 2122 (2005). 
13. M. Oubaha, M. Smaïhi, P. Etienne, P. Coudray, and Y. Moreau, J. Non-Cryst. Solids 318, 305 (2003).

14. L.W. Kelts and N.J. Armstrong, J. Mater. Res. 4, 423 (1989).

15. B.M. De Witte, D. Commers, and J.B. Uytterhoeven, J. Non- Cryst. Solids 202, 35 (1996).

16. F. Babonneau and J. Maquet, Polyhedron 19, 315 (2000).

17. T. Jermoumi, M. Smaïhi, and N. Hovnanian, J. Mater. Chem. 5(8), 1203 (1995).
18. Y. Sugahara, S. Okada, S. Sato, K. Kuroda, and C. Kato, J. NonCryst. Solids 167, 21 (1994).

19. Y. Sugahara, S. Okada, S. Sato, K. Kuroda and C. Kato, J. NonCryst. Solids 139, 25 (1992).

20. L. Bois, PhD Thesis, Paris VI (1993).

21. H. Marsmann, Oxygen-17 and Silicon-29 NMR Spectroscopy (Springer, Berlin, 1981).

22. L. Delattre, M. Roy, and F. Babonneau, J. Sol-Gel. Sci. Technol. 8, 567 (1997). 